\title{
"Say It Ain't So, Ben": Attributions for a Fallen Hero*
}

This study examines some well-known attributional tendencies in a unique situation. Specifically, it examines attributions for the unexpected fall of a Canadian hero, Ben Johnson, who was stripped of his Olympic gold medal for the use of anabolic steroids. The results reveal a reversal of the fundamental attributional bias and the use of base rate information in observers' attributions. The findings are interpreted and discussed in terms of Pyszczynski and Greenberg's (1987) biased hypothesis-testing model.

I first heard the news with disbelief. I still have trouble believing it because I realized that Ben would not do anything that dumb and ruin his reputation. He was obviously mishandled and misadvised. ... . Of all the people I have spoken to, friends and family alike, most of us believe Ben is an innocent man. .. . We are proud of Ben. He is the first genuine hero Canada has had in a long time. ... . We all have faith in him.

Toronto Sun, Friday, October 7, 1988

This letter to the editor relates the initial shock and disbelief felt by most Canadians after Ben Johnson was stripped of his gold medal and his world record in the 100-meter race at the Seoul Olympics, where he tested positive for a banned anabolic steroid. It also indicates the consuming interest in the event, the strong sense of identification with Ben, and the painful deliberations by average Canadians in order to salvage what they could from the affair. The Ben Johnson camp denied the use of anabolic steroids and claimed that the test result was due to sabotage. Coverage was extensive (each of the three major Toronto newspapers, where Ben Johnson makes his home, devoted four to eight pages a day to the story in the first week), but the media did not settle on any single explanation. Instead, an extraordinary range of hypotheses was entertained: it was suggested, for example, that the North Koreans had tampered with Ben's water bottle to cause a scandal that would would ruin the Olympics. These explanations were echoed by average Canadians, who made the affair the most important topic of conversation for at least two weeks.

This event offered an unprecedented oppor-

* The authors would like to thank John Bassilli and three anonymous reviewers for helpful comments on an earlier version of this paper. tunity to examine some well-documented attributional tendencies in a unique situation. It allowed us to investigate attributions not merely in a real-life situation (e.g., Burger 1985), but also in the case of a hero whose unexpected fall precipitated one of the most disappointing and most emotionally intense experiences in Canada in recent years. We wanted to know how such an unexpected outcome would affect observers' overall attributions to situational and dispositional factors, and how information seeking and base rate information would affect their attributions to these two causal loci.

Choice of these variables was suggested by Pyszczynski and Greenberg's (1987) biased hypothesis-testing model. That model seeks to account both for the hasty, top-of-the-head judgments reported in much of the attributional literature (e.g., Ross 1977; Taylor and Fiske 1978), and for the active hypothesis testing found in a few studies (e.g., Pyszczynski, Greenberg, and LaPrelle 1985). According to Pyszczynski and Greenberg, hasty judgments occur when events are nonproblematic and when they fit prior expectancies. Under these conditions, observers rely on the most perceptually salient information. Hence they overestimate the role of dispositional factors and underestimate the roles of both situational factors (Jones and Nisbett 1971) and base rate information (e.g., Tversky and Kahneman 1974) in the control of behavior.

When events are novel or unexpected, however, individuals engage in active hypothesis testing. This process consists of several sequential phases in which individuals generate hypotheses, select inference rules for evaluating them, and seek more attributionrelevant information. Because the unexpected 
events that precipitate the active hypothesistesting mode are frequently self-threatening, various motivational influences other than accuracy can affect the hypothesis-testing process. Thus the model focuses on the process of biased hypothesis testing, in which the concern for accuracy becomes secondary to the concern for defensive attributions.

The two conditions that Pyszczynski and Greenberg stipulate as necessary for arousing biased hypothesis testing are clearly fulfilled in the Ben Johnson affair. Specifically, the stripping of Ben's gold medal for steroid use was both unexpected and self-threatening to Canadians, who were basking in the reflected glory of his record-shattering victory (Cialdini et al, 1976). So strong was the association with this hero both before and after the Olympics that it is virtually certain that Canadians formed a "unit relationship" with him (Heider 1958). That is, they placed him and themselves in the same cognitive unit (a Canadian winner of a gold medal and twice world record holder), which was distinguished from everyone outside the unit in important ways.

Although Ben's unexpected fall should activate the active hypothesis-testing mode, the virtual certainty that Canadians also formed a unit relationship with him should cause observers to engage in a biased hypothesis-testing process. The activation of the biased hypothesis-testing process leads to interesting hypotheses about observers' attributions to dispositional and situational factors and to their use of base rate information. Research on the fundamental attributional bias suggests that when observers" epistemic curiosity is not aroused, they tend, as a result of the actor's perceptual saliency, to make more dispositional than situational attributions (Jones and Nisbett 1971). In the Ben Johnson affair, the actor's perceptual saliency was practically overwhelming. Ben's races were replayed ad nauseam; his every move was the focus of media attention. In contrast, his handlers remained relatively obscure and unknown. Presumably, then, if observers were disinterested in the event or had expected such behavior (i.e., drug use), they would have been prone to the fundamental attributional bias.

Indeed, overattribution to dispositional factors has been found to be robust and difficult to eliminate (Miller, Jones, and Hinkle 1981: Tetlock 1985), Studies con- ducted to learn whether it could be eliminated have succeeded by providing no information about the actor and by making situational factors salient (Ajzen, Dalto, and Blyth 1979) or by holding observers personally accountable for their attributions (Tetlock 1985). Neither of these conditions holds in the present case. We are predicting, however, that the arousal of the active hypothesistesting mode by Ben's unexpected fall will render observers less prone to the fundamental attributional bias and more attentive to base rate information (cf. Pyszczynski et al. 1985). In other words, the perceptual saliency effects that contribute to the overattribution effect should diminish when events arouse observers' epistemic curiosity.

This hypothesis can be specified further. Because we are postulating that observers tend to form a unit relationship with Ben, the unexpected negative outcome will be regarded as self-threatening. Hence observers should engage in a biased hypothesis-testing process, which should cause them to reverse their usual dispositional attributional tendencies and to make more situational, more actorlike attributions (cf. Burger 1985). Such attributions provide a defense against the implication that Canadians, in the immediate aftermath of Ben's fall, were generally unwilling to accept: that their hero "won" by cheating.

Because this study uses a naturally occurring event, there is no control group. In lieu of a control group we provide a more rigorous test of our hypothesis by comparing the attributions of those who followed the affair closely with those who followed it less closely. Because those who followed the affair most closely are most likely to form a unit relationship and to regard Ben's fall as self-threatening, we anticipate that they will make more situational and less dispositional attributions than those who followed it less closely.

Finally, let us address the question of accuracy in the fundamental attributional bias. Harvey, Town, and Yarkin (1981) observe that to speak of the fundamental attributional "error," as Ross (1977) initially termed the "bias," it is necessary to prove causality. When the data were collected for this study, the accuracy demanded by Harvey et al. was (fortuitously) unavailable. The evidence indicating that Ben took steroids knowingly, however, is now overwhelming. 
Thus his coach, Charlie Francis, in testimony before the Dublin Inquiry on March 1, 1989 , asserted that Ben had taken steroids knowingly for the past eight years. The interpretation of the findings presented here will be made in terms of two standards: the evidence available when the data were collected and the present evidence.

\section{METHOD}

\section{Subjects and Procedures}

Questionnaires pertaining to the Ben Johnson affair were distributed in two introductory and two second-year sociology courses at the Scarborough Campus, University of Toronto. Students were allowed up to 30 minutes to complete the questionnaire. Completion of the questionnaire was voluntary; 358 of an original 395 questionnaires were returned. The response rate thus surpassed 90 percent. To keep the Ns consistent across analyses, however, we eliminated from the sample all respondents with missing values on any of the variables reported here. This step results in an overall $\mathrm{N}$ of 338 (i.e., $5 \%$ of respondents were eliminated) and does not affect the results obtained when missing values are eliminated selectively.

All questionnaires were distributed within eight days of the official announcement that Ben Johnson had tested positive for steroid use. We monitored media coverage carefully during this period, so that we would know what information was available to respondents. Significantly, by the time data collection was completed, the media had reported only rumors of steroid use in Ben's club. In other words, the most damning evidence against Ben was reported well after the collection of data.

The questionnaire consisted of a series of scaled questions that dealt with attributions, attitudes, and perceptions of deviance, as well as background information on respondents and a few open-ended items. Here we focus on the attributional results. Attributions were measured by questions dealing with the causal locus for the use of steroids and by questions concerning responsibility for what had happened to Ben. For causal locus, respondents were asked to indicate the likelihood of each of the following altematives: that the results of the Olympic test could be in error; that Ben was taking steroids knowingly before the
Olympics; that he was taking steroids unknowingly (i.e., his coach or his doctor was administering them secretly); and, finally, that he was the victim of sabotage. These questions reflected the major hypotheses that emerged in the media.

For attribution of responsibility, respondents were asked to state how responsible both Ben and his handlers were for the incident. Again, this division of responsibility reflected the way in which the issue was framed in the media. All attributional questions were based on seven-point scales with labeled endpoints. Higher scores were labeled either "very likely" or "very responsible."

In addition to asking about attributions, we asked respondents how likely it was that Ben could have won the race without the use of steroids, and how likely it was that most track and field athletes used steroids as part of their training. Likelihood scores were measures on a seven-point scale with labeled endpoints ( 7 = "highly likely"). Respondents indicated on a seven-point scale with labeled endpoints how closely they followed the Ben Johnson affair $(7=$ "very closely"). They also were asked whether they had watched the live broadcast of Ben's race and what media sources (if any) they used to follow the event.

\section{RESULTS}

Because the data presented here are derived from a natural setting, the results are correlational rather than experimental. At the same time, the data afford the opportunity to examine attributional processes for an unexpected outcome that was highly salient and affectively involving for respondents. Evidence consistent with the latter situation is as follows. First, 82 percent of respondents stated that they had watched Ben's race live. Second, 94 percent of respondents reported that they had followed the ensuing affair in at least one media source; 60 percent reported that they had followed it in two or more media sources. Third, the mean rating of how closely respondents followed the affair was 5.66 on a seven-point scale.

Column 1 of Table 1 shows the attributions to the four causal loci and the attributions of responsibility to Ben and his handlers. As Table 1 reveals, respondents gave little credence to the view that the Olympic test could be in error. This finding suggests that despite the desire to see a hero as innocent. 
Table 1. Attributions for the Ben Johnson Affair

\begin{tabular}{|c|c|c|c|}
\hline & \multicolumn{3}{|c|}{$\begin{array}{l}\text { a. Mean Likelihood for } \\
\text { Different Causal Loci }\end{array}$} \\
\hline & Overall $^{\mathrm{B}}$ & $\begin{array}{l}\text { Follow } \\
\text { Closely }\end{array}$ & $\begin{array}{l}\text { Not } \\
\text { Follow } \\
\text { Closely }\end{array}$ \\
\hline Olympic test in error & $\begin{array}{l}2.08 \\
(1.42)^{b}\end{array}$ & $\begin{array}{l}2.17 \\
(1.42)\end{array}$ & $\begin{array}{c}2.02 \\
(1.43)\end{array}$ \\
\hline Using steroids knowingly & $\begin{array}{c}3.54 \\
(2.06)\end{array}$ & $\begin{array}{l}3.17 \\
(2.10)\end{array}$ & $\begin{array}{c}4.07 \\
(1.89)\end{array}$ \\
\hline $\begin{array}{l}\text { Using steroids } \\
\text { unknowingly }\end{array}$ & $\begin{array}{c}4.60 \\
(1.97)\end{array}$ & $\begin{array}{c}4.94 \\
(2.05)\end{array}$ & $\begin{array}{c}4.13 \\
(1.75)\end{array}$ \\
\hline \multirow[t]{2}{*}{ Victim of sabotage } & $\begin{array}{c}3.83 \\
(2.18)\end{array}$ & $\begin{array}{l}3.94 \\
(2.36)\end{array}$ & $\begin{array}{c}3.69 \\
(1.90)\end{array}$ \\
\hline & \multicolumn{3}{|c|}{$\begin{array}{l}\text { b. Mean Attribution } \\
\text { of Responsibility }\end{array}$} \\
\hline \multicolumn{4}{|c|}{ Attribution of Responsibility } \\
\hline Ben & $\begin{array}{c}2.93 \\
(1.93)\end{array}$ & $\begin{array}{c}3.53 \\
(1.92)\end{array}$ & $\begin{array}{c}4.50 \\
(1.84)\end{array}$ \\
\hline Ben's handlers & $\begin{array}{c}5.79 \\
(1.29)\end{array}$ & $\begin{array}{c}6.05 \\
(1.12)\end{array}$ & $\begin{array}{c}5.41 \\
(1.44)\end{array}$ \\
\hline
\end{tabular}

- Higher score indicates greater likelihood or greater responsibility.

${ }^{-}$Standard deviations are given in brackets.

c $N=198$ for follow closely; $N=140$ for not follow closely.

people do not accept hypotheses that are utterly refuted by the evidence (cf. Pyszczynski and Greenberg 1987, pp. 328--30). Table 1 reveals further that respondents were more likely to think that Ben was taking steroids unknowingly than knowingly, $t(337)=$ $5.49, p<.001$. In other words, and contrary to the fundamental attributional bias, situational factors were given greater causal import than the actor or his dispositions. Further, respondents thought it as likely that he was the victim of sabotage as that he was taking steroids knowingly, $t(337)=1.42$, $p>.1$.

The results for the attribution of responsibility reveal that more responsibility was assigned to Ben's handlers than to the actor himself, $t(337)=15.41, p<.001$. Taken in conjunction, the results in Table 1 reveal that observers in this case were not prone to the fundamental attributional bias. For both sets of results, situational factors were given greater causal importance than dispositional factors.

Table 2 shows the correlations between the other variables and the attributions made for the affair. The results in Row 1 of Table 2 reveal that following the event closely was related positively to making situational attributions (unknowingly, Ben's handlers) and negatively to making attributions to the actor (knowingly, Ben). In other words, following the event closely was associated with a reversal of the fundamental attributional bias.

To examine these results further, we used a median split to divide respondents into those who followed the affair closely and those who did not. The results of this median split are given in Columns 2 and 3 of Table 1. As the aforementioned correlations would indicate. comparisons of the means of those who followed the affair closely with those who did not reveal that the former attributed less responsibility to Ben than did the latter, $t(337)=4.70, p<.001$, and more responsibility to his handlers, $t(337)=$ $-4.55, p<.001$; they were more likely to believe that he took drugs unknowingly, $t(337)=-3.85, p<.001$, and less likely to believe that he used them knowingly, $t(337)=4.09, p<.001$. In other words, those who followed the affair closely consistently made fewer internal and more external attributions than those who did not follow it closely.

Comparisons of the mean attributions within groups are necessary only among those who did not follow the affair closely. (For those who followed it closely, the means and the results reported above reveal an accentuation of the overall reversal of the fundamental attributional bias.) Interestingly, those who did not follow the affair closely were no more likely to believe that Ben took steroids unknowingly than knowingly, $t(139)=0.21, p>.1$. They did, however, assign more blame to Ben's handlers than to Ben himself, $t(139)=5.36, p<.001$. In short, this group shows a weaker tendency to reverse the fundamental attribution bias, pre-

Table 2. Correlations with Attributions

\begin{tabular}{lccccc}
\hline & & & Atributions & \\
\cline { 2 - 6 } Variable & Knowingly & Unknowingly & Sabotage & Ben & Handler \\
\hline Follow closely & $-.23^{* *}$ & $.22^{* *}$ & -.02 & $-.21^{* *}$ & $.27^{* *}$ \\
Win without steroids & $-.38^{* *}$ & $.27^{* *}$ & $.28^{* *}$ & $-.40^{* *}$ & .00 \\
Athletes use steroids & $.17^{* *}$ & .02 & $-.15^{*}$ & $.14^{*}$ & $.29^{* *}$ \\
\hline$* \mathrm{p}<.01 ; * * \mathrm{p}<.001$. & & & &
\end{tabular}


sumably because they were less interested and hence less threatened by Ben's fall.

In Table 2, the results in Row 2 show that faith in Ben's abilities to win without the use of steroids was associated positively with attributions to situational factors and negatively with attributions to the actor. That is, those who thought Ben likely to win without steroids clearly avoided blaming Ben himself. and even retained faith in the sabotage hypothesis

Finally, the results in Row 3 reveal that self-generated base rate information about the use of steroids among athletes was related significantly to attributions. Belief that steroid use was widespread was associated positively with attributions to Ben as well as to his handlers. Moreover, belief in steroid use was associated with respondents' discounting the sabotage hypothesis. In contrast with the findings of most prior research, then. respondents do not ignore base rate information.

\section{DISCUSSION}

The data presented here provide novel and substantial correlational support for Pyszczynski and Greenberg's (1987) biased hypothesistesting model. For a real-life outcome that was both unexpected and self-threatening. observers entertained a wide range of hypotheses and were less prone to the errors associated with perceptual saliency effects. The latter occurred in a situation in which, as noted previously, the actor's perceptual saliency was practically overwhelming and far exceeded the attention given to his handlers.

The present results reveal a strong tendency to attribute Ben's unexpected Olympic downfall to situational rather than dispositional factors. This finding is in contrast to a real-life study by Burger (1985), which revealed that observer's attributions for a losing team started as dispositional and became ever more dispositional over time. Burger explained this finding by suggesting that observers did not form a unit relationship with the losing team and thus felt no need to make defensive attributions. Our results appear to support Burger's speculative explanation. In the present case it seems plausible that the great majority of Canadians formed a unit relationship with Ben: hence observers made the more defensive, more actorlike attributions that would follow from the biased hypothesis-testing model. It is consistent with our interpretation of the findings that such defensive attributions were stronger among those who followed the affair closely than among those who did not.

The present results support a further implication of that model. In keeping with Pyszczynski and Greenberg's (1987) suggestion that observers will not accept hypotheses which are utterly refuted by the evidence, we found that respondents did not believe the results of the Olympic test to be in error. Yet Pyszczynski and Greenberg (1987, p. 328 ) also suggest that individuals making biased attributions will retain unlikely hypotheses by not generating either the inference rules or the data necessary to test them. In the present study, observers held two hypotheses for which the supporting evidence was slight.

First, respondents thought it most likely that Ben was taking steroids unknowingly. Moreover, this belief was significantly stronger among those who followed the affair closely than among those who followed it less closely. Yet media coverage of the affair in the days preceding the collection of data had already rendered this hypothesis unlikely. Specifically, the claim that an athlete could be taking steroids unknowingly was rejected widely by doctors and athletes: they noted that the gains in strength and weight which follow from steroid use could not escape the attention of world-class athletes, who must monitor their own conditioning carefully. Of course the evidence currently being given to the Dubin Inquiry shows that our respondents' attributions were erroneous.

Second, the hypothesis which held that Ben was the victim of sabotage was even more implausible because the test results indicated long-term use of the substance and because the Olympic testing committee publicly disavowed the possibility that sabotage could account for the depressed levels of testosterone found in Ben's urine. Thus it appears that Canadians who identified closely with their hero and were reluctant to view him as guilty generated novel hypotheses but did not subject them to rigorous testing. Those who followed the affair most closely were either ignoring or denying the conclusions that were emerging in the media.

At the same time, respondents were sensitive to base rate information and used it in a potentially logical fashion. According o the data, belief that steroid use was wide 
spread was associated positively with blaming Ben and his handlers, and negatively with the sabotage hypothesis. If steroid use is indeed widespread, it follows that Ben is likely to be using them. The responsibility rests with Ben and with his handlers, but there is less need to be defensive about his actions because they are less unexpected and less reprehensible in a context where everyone is using steroids.

Of course, the correlation could be due to the fact that respondents who thought Ben used steroids felt it less threatening to believe that their use is widespread among athletes. This interpretation, which cannot be ruled out, involves a defensive bias rather than a concern with accuracy. In either case it is clear that respondents did not simply ignore base rate information.

Although our analysis has focused on the influence of unexpected and self-threatening outcomes on attributions, it also contains an implicit concern with societal influences on attribution. Whereas Tetlock (1985) found that accountability eliminated the fundamental attribution bias, we are similarly concerned with the public dimension of attributions: specifically, attributions as an aggregate social phenomenon. Attributional research has conceptualized attributions as a property of atomistic individuals who usually do not communicate their inferences. In the Ben Johnson affair, however, the media and ordinary Canadians made a wide range of attributions and discussed them actively. More generally, when events are unexpected and/or threatening, individuals and their significant others may not only entertain and discuss a range of attributions, but may even collaborate and collude to produce acceptable ascriptions of causality. The social aggregation of attributions seems worthy of further investigation.

\section{REFERENCES}

Ajzen, I., C.A. Dalto, and D.P. Blyth, 1979. "Consistency and Bias in the Attribution of Attitudes." Journal of Personality and Social Psychology 37: 1871-76.

Burger, J.M. 1985. "Temporal Effects on Attributions for Academic Performances and Reflected-Glory Basking." Social Psychology Quarterly 48:330-36.

Cialdini, R.B., R.J. Border, A. Thorne, M.R. Walker. S. Freeman, and R.L. Sloan. 1976. "Basking in Reflected Glory: Three (Football) Field Studies." Journal of Personality and Social Psychology 34 366-75.

Harvey, J.H., J.P. Town, and K.L. Yarkin. 1981, "How Fundamental Is "The Fundamental Attribution Error"? Journal of Personality and Social Psychology 40 . 346-49.

Heider. F. 1958. The Psychology of Interpersonat Relations. New York: Wiley.

Jones, E.E. and R.E. Nisbett. 1971. The Actor and the Observer: Divergent Perspectives of the Causes of Behavior. Morristown, NJ: General Learning.

Miller, A.G., E.E. Jones, and S. Hinkle, 1981. "A Robust Attribution Error in the Personality Domain," Journal of Experimental Social Psychologv 17 : $587-600$.

Pyszczynski, T. and J. Greenberg. 1987. "Toward an Integration of Cognitive and Motivational Perspectives on Social Inference: A Biased Hypothesis-Testing Model." Pp. 297-340 in Advances in Experimental Social Psychology. Volume 20, edited by L. Berkow. itz. New York: Academic Press

Pyszczynski, T., J. Greenberg, and J. LaPrelle. 1985. "Social Comparison after Success and Failure: Biased Search for Information Consistent with a Self-Serving Conclusion." Journal of Experimental Social Psychology 21: 195-211.

Ross, L. 1977. "The Intuitive Psychologist and His Shortcomings: Distortions in the Attribution Process." Pp. 172-220 in Advances in Experimental Social Psychology, Volume 10, edited by L. Berkowitz. New York: Academic Press.

Taylor, S. and S. Fiske. 1978. "Salience, Attention, and Attribution: Top of the Head Phenomena." Pp 249-288 in Advances in Experimental Social Psychot ogy, Volume 1, edited by L. Berkowitz. New York: Academic Press.

Tetlock, P.E. 1985. "Accountability: A Social Check on the Fundamental Attribution Error." Social Psychologv" Quarterly 48: 227-36.

Tversky, A. and D. Kahneman. 1974. "Judgment under Uncertainty: Heuristics and Biases." Science 185 1124-31.

Sheldon Ungar is Associate Professor of Sociology at Scarborough Campus, University of Toronto. He is currently doing research on the social psychology of the arms race.

Aysan Sev'er is Assistant Professor of Sociology at Scarborough Campus. University of Toronto. Het interests are in the areas of small groups and gender relations. 